\title{
Numerical and CFD Design of Heat Exchanger Used to Biomass Combustion
}

\author{
Marian Pafcuga ${ }^{1, *}$, Andrej Kapjor ${ }^{1}$, David Hecko $^{1}$, and Martin Vantuch ${ }^{1}$ \\ ${ }^{1}$ Department of Power Engineering, Faculty of Mechanical Engineering, University of Zilina, \\ Univerzitna 1, 01026 Zilina, Slovak republic
}

\begin{abstract}
The article describes the design of a heat exchanger used for biomass combustion. The design takes into account simple maintenance of the exchanger, low input costs of construction and the highest possible efficiency. In the design is used the tubular type of heat exchanger. The construction consists of a tubular part - flue gas part, inter-tube space heat transfer medium space. The output of the numerical model, CFD model is the heat transfer coefficient, heat exchanger power and final comparison of CFD and numerical model outputs.
\end{abstract}

\section{Numerical design of heat exchanger}

We know various divisions of types of exchangers in terms of construction, type of media used, according to the purpose of use, the meaning of the flow of heat transfer media. When designing the exchanger, emphasis is placed on the smallest possible dimensional requirements, low costs, high reliability and easy maintenance. During process of burning biomass, it is necessary to take into account in particular the simplicity of construction, but also the easiest possible maintenance of equipment. The combustion of biomass, especially straw, produces emissions of solid pollutants, which gradually pollute the heat exchanger. Therefore, in our case, we decided for a tubular type exchanger. This type of exchanger enables the introduction of continuous cleaning, but also simple maintenance, when even after equipment failures, it is possible to replace individual parts (pipes) of the equipment that are exposed to the adverse corrosive effects of biomass flue gases $[1,2]$.

The exchanger consists of two identical parts, which are interchangeable. In the event of a fault, the device can also work with one part with reduced power [3]. In this way, it is possible to maintain the functionality of the device - maintaining the operation of the heating system, repairing a non-functional part of the exchanger and quick re-commissioning of the device. The proposed exchanger uses flue gas and water heat media without segment baffles.

\footnotetext{
*Corresponding author: marian.pafcuga@ffstroj.uniza.sk
} 


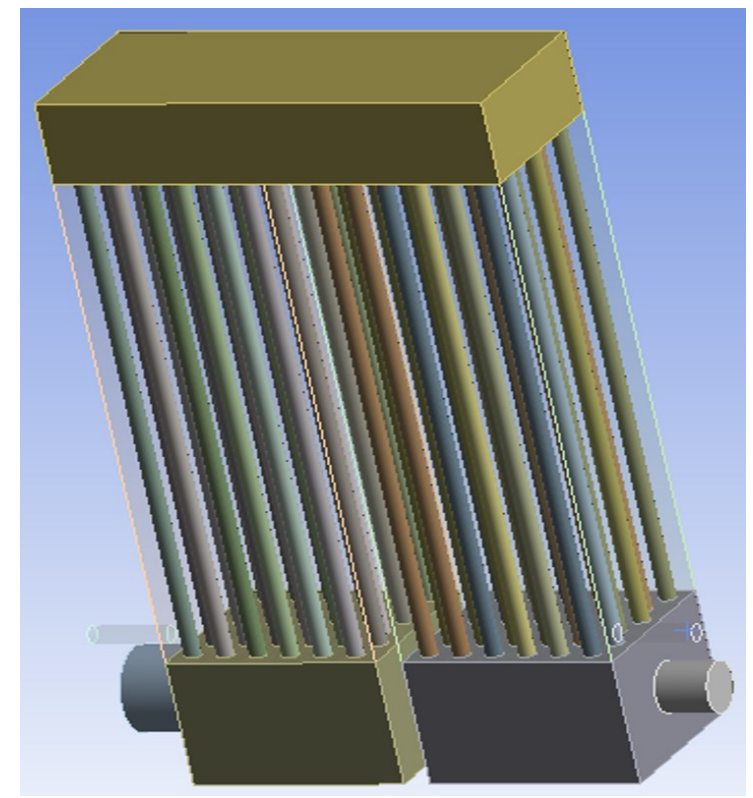

Fig. 1. Designed exchanger.

\subsection{Calculation and design of heat exchanger}

Two basic equations are used to calculate the heat exchanger parameters.

Heat balance equation:

$$
\dot{Q}=m_{1 .} c_{1}\left(t_{11}-t_{12}\right)=m_{2} \cdot c_{1} .\left(t_{22}-t_{21}\right)
$$

Where: $\dot{Q}$ - power of heat exchanger [W], $m_{1}$ - flow of flue gas $\left[\mathrm{kg} . \mathrm{s}^{-1}\right], c_{1}$ - specific heat capacity of flue gas $\left[\mathrm{J}^{\mathrm{kg}}{ }^{-1} \mathrm{~K}^{-1}\right], t_{11}$ - Inlet temperature - flue gas $\left[{ }^{\circ} \mathrm{C}\right], t_{12}$ - outlet temperature - flue gas $\left[{ }^{\circ} \mathrm{C}\right], m_{2}$ - flow of water $\left[\mathrm{kg} . \mathrm{s}^{-1}\right], c_{2}$ - specific heat capacity of water $\left[\mathrm{J} \cdot \mathrm{kg}^{-1} \mathrm{~K}^{-1}\right]$, $t_{21}$ - inlet temperature - water $\left[{ }^{\circ} \mathrm{C}\right], t_{22}$ - Outlet temperature - water $\left[{ }^{\circ} \mathrm{C}\right]$.

Heat transfer equation:

$$
\dot{Q}=k \cdot \Delta t . S
$$

Where: $\dot{Q}$ - power of heat exchanger [W], $k$ - heat transfer coefficient $\left[\mathrm{W} \cdot \mathrm{m}^{-1} \cdot \mathrm{K}^{-1}\right], \Delta t-$ mean logarithmic temperature gradient for counter flow $\left[{ }^{\circ} \mathrm{C}\right], S$ - area of heat exchanger $\left[\mathrm{m}^{2}\right]$.

To calculate heat exchanger length, we need to know overall heat transfer coefficient used to calculate necessary heat transfer area of heat exchanger. Input parameters are listed in Table 1. Dimensions of heat exchanger are shown in Figure 2. Heat transfer coefficient consist of convection coefficient in pipe side (flue gas) and of convection coefficient of inner - tube space (water). To calculate the coefficients, it is necessary to know the properties of individual heat transfer media at the points of their mean temperatures [4].

Table 1. Heat exchanger design inputs [5]. 


\begin{tabular}{|c|c|c|}
\hline Inlet temperature - water & ${ }^{\circ} \mathrm{C}$ & 50 \\
\hline Outlet temperature - water & ${ }^{\circ} \mathrm{C}$ & 80 \\
\hline Inlet temperature - flue gas & ${ }^{\circ} \mathrm{C}$ & 840 \\
\hline Outlet temperature flue gas & ${ }^{\circ} \mathrm{C}$ & 150 \\
\hline Demanded power & $\mathrm{kW}$ & 20 \\
\hline
\end{tabular}

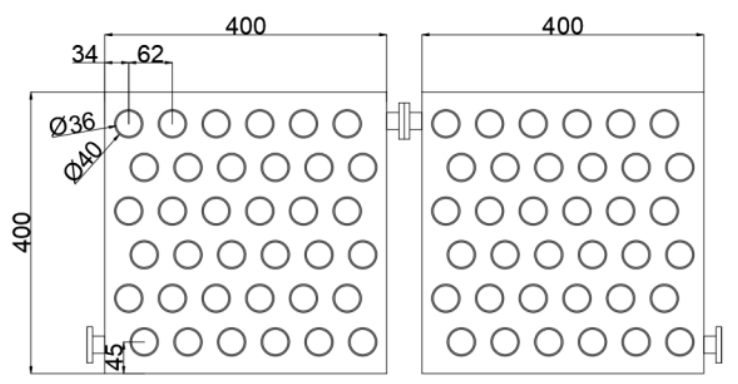

Fig. 2. Dimensions of designed heat exchanger.

\subsubsection{Pipe area - flue gas}

Flue gas will flow in pipe area. Outer diameter of pipes is 40 millimetres. The flue gas properties are calculated for an average temperature of $495^{\circ} \mathrm{C}$, flow of $207 \mathrm{~m}^{3} \mathrm{~h}^{-1}$. To calculation are used criterial equations. Flue gas properties are shown in Table 2.

Table 2. Flue gas properties [3].

\begin{tabular}{|c|c|c|}
\hline Inlet temperature - flue gas & ${ }^{\circ} \mathrm{C}$ & 840 \\
\hline Outlet temperature flue gas & ${ }^{\circ} \mathrm{C}$ & 150 \\
\hline Mean temperature - flue gas & ${ }^{\circ} \mathrm{C}$ & 495 \\
\hline Density & $\mathrm{kg} . \mathrm{m}^{-1}$ & 0.46 \\
\hline Specific heat capacity & $\mathrm{J}^{\circ} \mathrm{kg}^{-1} \mathrm{~K}^{-1}$ & 1095 \\
\hline Kinematic viscosity & $\mathrm{m}^{2} \mathrm{~s}^{-1}$ & $9.10^{-5}$ \\
\hline Dynamic viscosity & $\mathrm{Pa}^{-\mathrm{s}}$ & $4.10^{-5}$ \\
\hline Thermal conductivity coefficient & $\mathrm{W} \cdot \mathrm{m}^{-1} \mathrm{~K}^{-1}$ & 0.053 \\
\hline Reynolds number & - & 723.36 \\
\hline Prandtl number & - & 0.83 \\
\hline Nusselt number & - & 4.59 \\
\hline Convection coefficient - flue gas & $\mathbf{W} . \mathbf{m}^{-1} \mathbf{K}^{-2}$ & $\mathbf{7 . 6 4}$ \\
\hline
\end{tabular}




\subsubsection{Inner pipe space - water}

Water will flow in inner pipe space. Inner diameter of pipe is 32 millimetres. The water properties are calculated for an average temperature of $65^{\circ} \mathrm{C}$, flow of $0.59 \mathrm{~m}^{3} \mathrm{~h}^{-1}$. To calculation are used criterial equations. Scheme of tube bundle is shown in Figure 1. Water properties are shown in Table 3.

Table 3. Water properties [2].

\begin{tabular}{|c|c|c|}
\hline Inlet temperature - water & ${ }^{\circ} \mathrm{C}$ & 50 \\
\hline Outlet temperature - water & ${ }^{\circ} \mathrm{C}$ & 80 \\
\hline Mean temperature - water & ${ }^{\circ} \mathrm{C}$ & 495 \\
\hline Density & $\mathrm{kg} \cdot \mathrm{m}^{-1}$ & 0.46 \\
\hline Specific heat capacity & $\mathrm{J}^{\circ} \mathrm{kg}^{-1} \mathrm{~K}^{-1}$ & 1095 \\
\hline Kinematic viscosity & $\mathrm{m}^{2} \mathrm{~s}^{-1}$ & $9.10^{-5}$ \\
\hline Dynamic viscosity & $\mathrm{Pa}^{-\mathrm{s}}$ & $4.10^{-5}$ \\
\hline Thermal conductivity coefficient & $\mathrm{W} . \mathrm{m}^{-1} \mathrm{~K}^{-1}$ & 0.053 \\
\hline Reynolds number & - & 1964 \\
\hline Prandtl number & - & 0.12 \\
\hline Nusselt number & - & 18.95 \\
\hline Convection coefficient - water & $\mathbf{W} . \mathbf{m}^{-1} \mathbf{K}^{-\mathbf{2}}$ & $\mathbf{3 2 1 . 4 5}$ \\
\hline
\end{tabular}

\subsection{Final design of heat exchanger}

Results of calculation are shown in Table 4. Final length of heat exchanger is 1800 millimetres, and overall heat transfer coefficient is $7.42 \mathrm{~W} \cdot \mathrm{m}^{-1} \mathrm{~K}^{-1}$.

Table 4. Final heat exchanger design.

\begin{tabular}{|c|c|c|}
\hline Inlet temperature - water & ${ }^{\circ} \mathrm{C}$ & 50 \\
\hline Outlet temperature - water & ${ }^{\circ} \mathrm{C}$ & 80 \\
\hline Inlet temperature - flue gas & ${ }^{\circ} \mathrm{C}$ & 840 \\
\hline Outlet temperature flue gas & ${ }^{\circ} \mathrm{C}$ & 150 \\
\hline Demanded power & $\mathrm{kW}$ & 20 \\
\hline Computed power & $\mathrm{kW}$ & 20.011 \\
\hline Inner diameter of pipes & $\mathrm{mm}$ & 32 \\
\hline Outer diameter of pipes & $\mathrm{mm}$ & 40 \\
\hline
\end{tabular}




\begin{tabular}{|c|c|c|}
\hline Pipe spacing & $\mathrm{mm}$ & 62 \\
\hline Number of pipes & $\mathrm{pcs}$ & 36 \\
\hline Length of heat exchanger & $\mathbf{m m}$ & $\mathbf{1 8 0 0}$ \\
\hline Width of heat exchanger & $\mathrm{mm}$ & 400 \\
\hline Overall heat transfer coefficient & $\mathbf{W} \cdot \mathbf{m}^{-\mathbf{1}} \mathbf{K}^{-\mathbf{1}}$ & $\mathbf{7 . 4 2}$ \\
\hline
\end{tabular}

\section{CFD design of heat exchanger}

We designed CFD model for pipe area - flue gas in Ansys 20.1 - Workbench to comparison and verification our numerical model. CFD model was implemented in Fluid Flow (Fluent) flow analysis system. For the calculation was used simplified 3D model with flue-gas phase. In model is used tetrahedral mesh shown inf Figure 3 with 2508553 elements. To calculation was used K- $\varepsilon$ model with scalable wall function. Input parameters are listed in Table 5. Setup converged $[6,7]$.

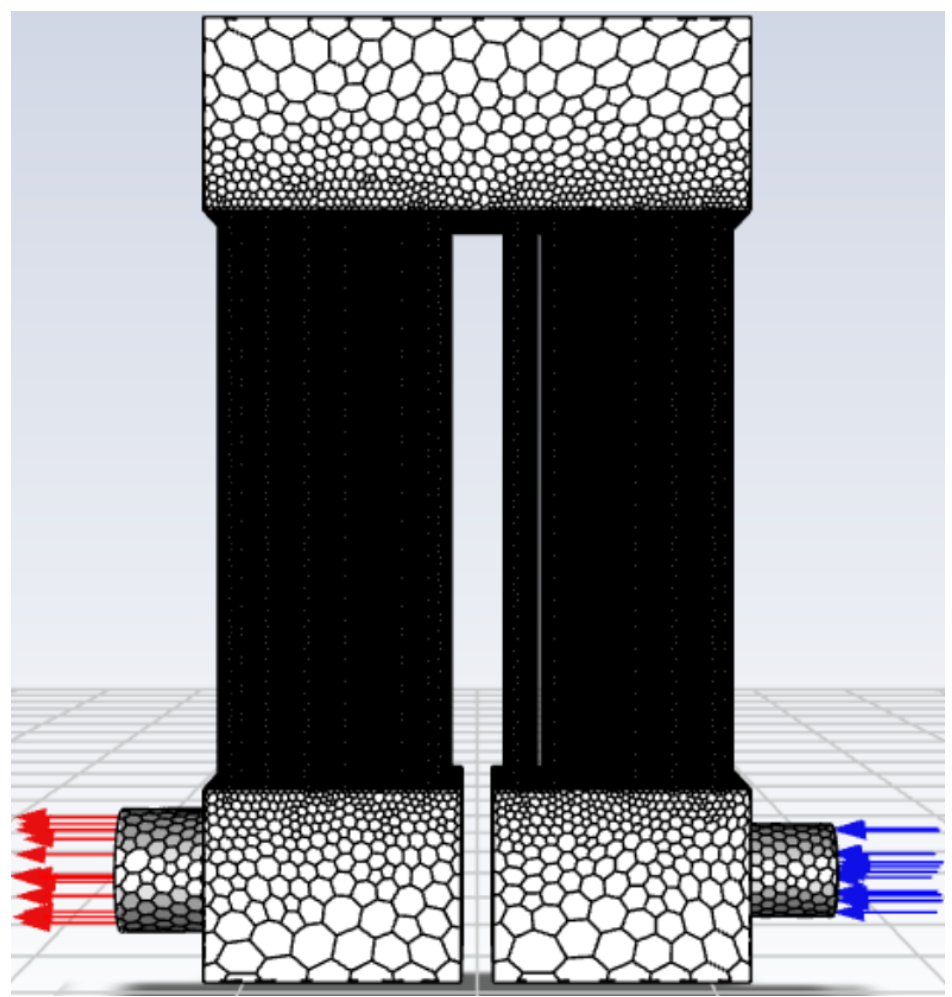

Fig. 3. Heat exchanger mesh.

Table 5. Heat exchanger design inputs. 


\begin{tabular}{|c|c|c|}
\hline Inlet temperature & ${ }^{\circ} \mathrm{C}$ & 840 \\
\hline Inlet flow & $\mathrm{m}^{3} \mathrm{~h}^{-1}$ & 207 \\
\hline Temperature of wall & ${ }^{\circ} \mathrm{C}$ & 65 \\
\hline
\end{tabular}

As result of calculation was power of the exchanger, the resulting temperature Figure 4. and velocity field Figure 5. Heat power was calculated to $19.311 \mathrm{~kW}$. From temperature field is obvious that outlet temperature of outlet flow of flue gas is $150{ }^{\circ} \mathrm{C}$. Velocity field shown that mean velocity is around $2 \mathrm{~m} \cdot \mathrm{s}^{-1}$.

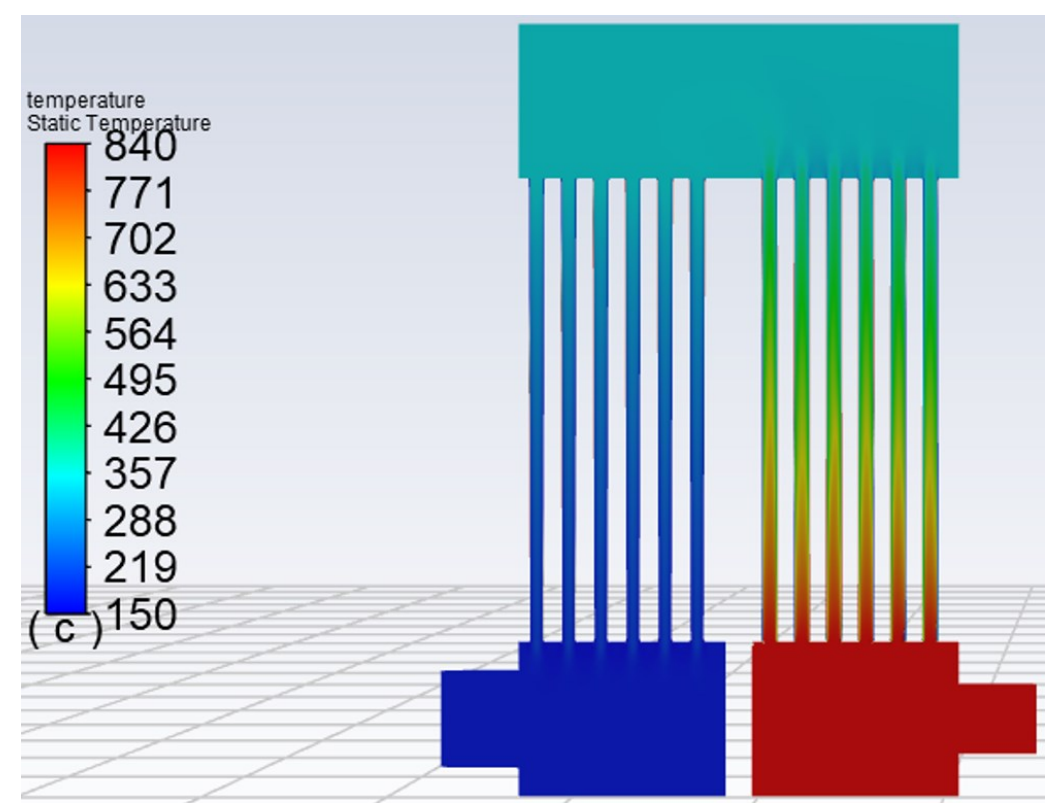

Fig. 4. Temperature field of designed heat exchanger - flue-gas side. 


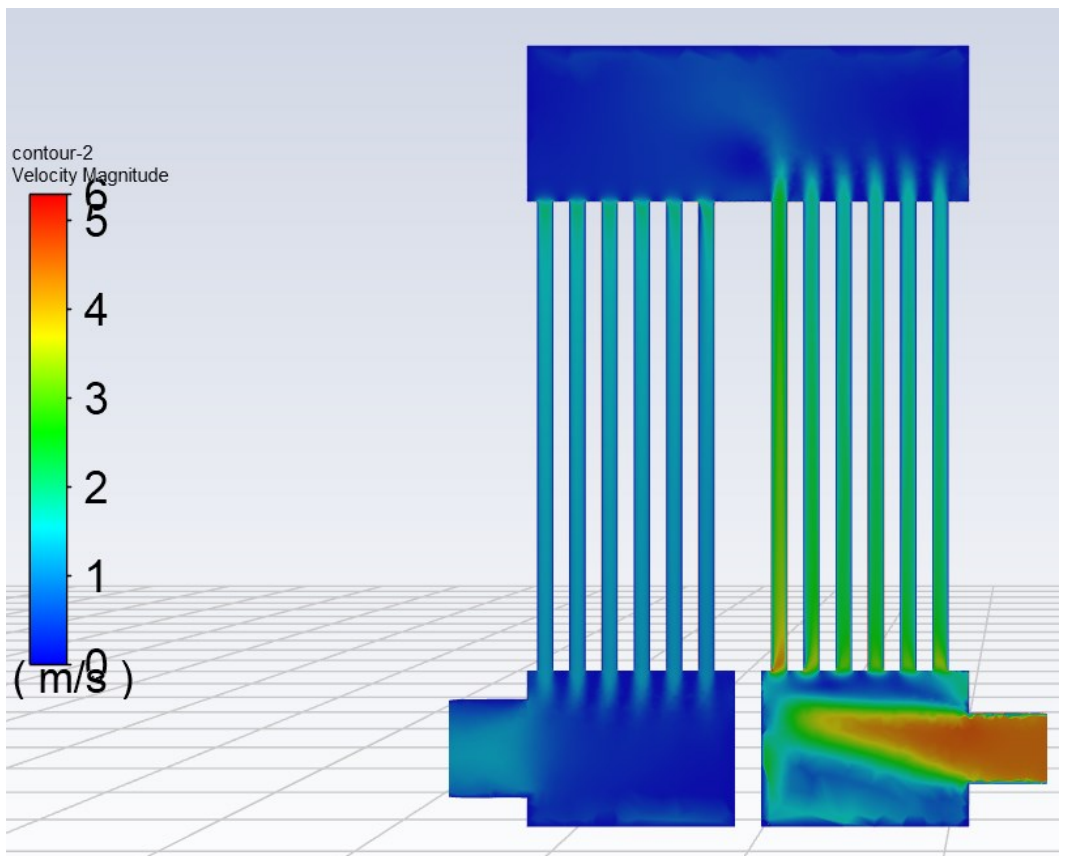

Fig. 5. Velocity field of designed heat exchanger - flue-gas side.

\section{Comparison of results from numerical model}

Designed models allows comparison of numerical and CFD models. From final temperature field Figure 4. we can see, that outlet temperature is similar to input of numerical model. From velocity field Figure 5 we can see that that mean velocity of flow flue gas is similar to calculated velocity of numerical model. From Figure 6 we can see main difference between power curve calculated by numerical model and CFD model. This difference is due to different way of calculation overall heat transfer coefficient. To final calculation is necessary verify results with measurement of real model, design final equation, which can be used to calculate properties of same type heat exchanger as is shown in Figure 1 in future designs. Model is used to simulate heat transform from flue-gas to water.

Comparison of results from CFD and numerical model

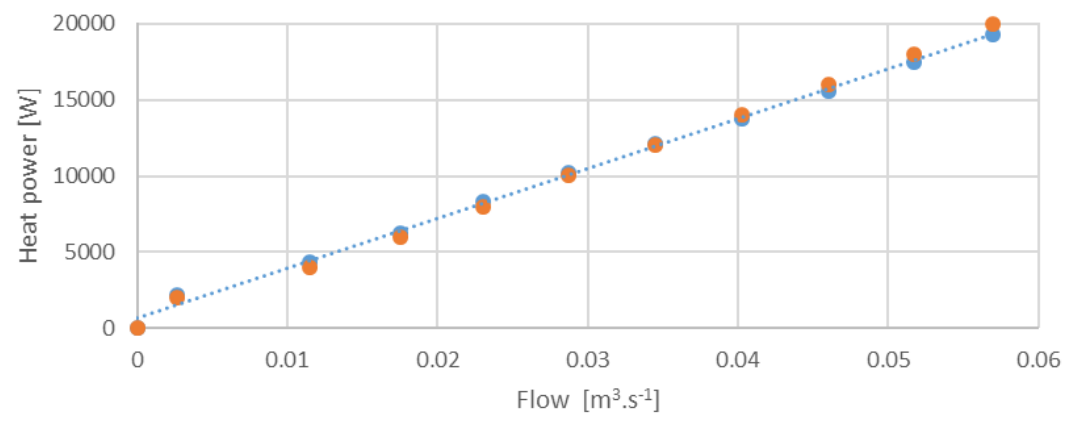

- Numerical model CFD simulation

Fig. 6. Comparison of results from CFD and numerical model. 
This article was supported by project VEGA 1/0479/1 "Influence of combustion conditions on the production of solid pollutants in small heat sources" and by project KEGA 033ŽU-4/2018 "Heat sources and environmental pollution".

\section{References}

1. S. Gavlas, P. Ďurčanský, R. Lenhard, J. Jandačka, Mathematical simulation of heat exchanger working conditions. EPJ web of conferences., 92 (2015)

2. J. Jandačka, M. Holubčík, Mobile Networks \& Applications, 25/3, 904-912 (2020)

3. J. Jandačka, M. Holubcik, S. Papucik, R. Nosek, Acta Montanistica Slovaca, 17, 283289 (2012)

4. F. P. Icropera, D. P. Dewitt, T. L. Bergman, A. S. Lavine, Fundamentals of Heat and Mass Transfer, 710-720 (2007)

5. M. Holubčík, J. Jandačka, P. Durčanský, Energy Properties of Wood Pellets Made from the Unusual Woody Plants, AIP Conference Proceedings, 1768 (2016)

6. Fluent Ansys, Tutorial guide (1993)

7. R. Lenhard, K. Kaduchová, Š. Papučík. Analysis of the fill amount influence on the heat performance of heat pipe. Analysis of the fill amount influence on the heat performance of heat pipe, 1608, 146-152 (2014) 